University of Nebraska - Lincoln

DigitalCommons@University of Nebraska - Lincoln

USDA National Wildlife Research Center - Staff

Publications

U.S. Department of Agriculture: Animal and Plant Health Inspection Service

2012

Avian use of solid waste transfer stations

Brian E. Washburn

United States Department of Agriculture, brian.e.washburn@aphis.usda.gov

Follow this and additional works at: https://digitalcommons.unl.edu/icwdm_usdanwrc

Washburn, Brian E., "Avian use of solid waste transfer stations" (2012). USDA National Wildlife Research Center - Staff Publications. 1210.

https://digitalcommons.unl.edu/icwdm_usdanwrc/1210

This Article is brought to you for free and open access by the U.S. Department of Agriculture: Animal and Plant Health Inspection Service at DigitalCommons@University of Nebraska - Lincoln. It has been accepted for inclusion in USDA National Wildlife Research Center - Staff Publications by an authorized administrator of DigitalCommons@University of Nebraska - Lincoln. 


\title{
Avian use of solid waste transfer stations
}

\author{
Brian E. Washburn* \\ United States Department of Agriculture, Wildlife Services, National Wildlife Research Center, 6100 Columbus Avenue, Sandusky, OH 44870, USA
}

\section{A R T I C L E I N F O}

\section{Article history:}

Received 8 August 2011

Received in revised form

16 November 2011

Accepted 16 November 2011

Available online 15 December 2011

\section{Keywords:}

Birds

Solid waste management

Transfer stations

Wildlife

\begin{abstract}
A B S T R A C T
Transfer stations are an important component of modern solid waste management systems. Solid waste management facilities (e.g., landfills) are very attractive to and used by many birds, resulting in a variety of health and safety problems, including disease transmission to humans and increased risk of wildlife-aircraft collisions. In the United States, the Federal Aviation Administration recommends municipal solid waste management facilities (e.g., landfills, transfer stations) not be sited within $8 \mathrm{~km}$ of an airport. Little information is available regarding the attractiveness of transfer stations to birds or the factors that might influence avian use, particularly on a national scale. The objectives of my study were to: (1) quantify avian use of transfer stations, (2) determine if building design features influence their attractiveness to birds, and (3) determine if other factors (e.g., season, geographic location, operational procedures) influence bird use. Twenty-nine waste transfer facilities and 4 control sites, located in 7 states (representative of various U.S. geographical regions) were studied. Avian abundance and activity was quantified at each facility and control site twice per week for one year. Nuisance bird species commonly observed using transfer stations (e.g., feeding on refuse) included gulls, European starlings, and crows. Patterns of wildlife use at transfer stations varied by season, geographic location, transfer station building design, and on-site management characteristics. Overall, this study demonstrates that wildlife use of transfer stations, particularly by nuisance birds, can be substantial.
\end{abstract}

Published by Elsevier B.V.

\section{Introduction}

Management and disposal of municipal solid waste is a major challenge world-wide, particularly in highly urbanized areas and in developing countries (Kollikkathara, Feng, \& Stern, 2009; Zhenshan, Lie, Xiao-Yan, \& Yu-mei, 2009). Solid waste transfer stations (hereafter, transfer stations) are important parts of modern solid waste management systems, within both metropolitan and rural areas (Bovea, Powell, Gallardo, \& Capuz-Rizo, 2007; EPA, 2002; Zhen-shan et al., 2009). Transfer stations are light-industrial facilities where municipal solid waste is unloaded from smaller refuse collection trucks (e.g., curbside collection trucks) and reloaded into larger transport vehicles (e.g., container trucks, rail cars) for transport to a final disposal site, such as a landfill or materials recovery facility (Bovea et al., 2007; EPA, 2002). Recently, there has been an increase in the number of transfer stations within municipal solid waste management systems, a trend that will likely continue into the future (Kollikkathara et al., 2009; Rahman \& Kuby, 1995).

Waste management facilities (e.g., traditional putrescible-waste landfills) provide abundant feeding opportunities for scavenging birds and thus large numbers of birds, especially gulls (Larus spp.),

\footnotetext{
* Tel.: +1 419625 0242; fax: +1 4196258465

E-mail address: brian.e.washburn@aphis.usda.gov
}

corvids (Corvus spp.), and European starlings (Sturnus vulgaris), are frequently present at such locations (Baxter \& Allan, 2006; Belant, Seamans, Gabrey, \& Dolbeer, 1995; Coulson, Butterfield, Duncan, \& Thomas, 1987; Rock, 2005). Large concentrations of scavenging birds at waste management facilities often lead to a variety of problems, including interference with daily operations of the facilities, nuisance issues for neighboring landowners and local residents, and threats to public health and human safety. Gulls, European starlings, rock pigeons (Columba livia), and other birds are known carriers of human pathogens (e.g., Salmonella, Escherichia coli, avian botulism) and can contaminate water supplies through defecation and carrying waste off-site (Benton, Khan, Monaghan, Richards, \& Sneddon, 1983; Monaghan, Sheddon, Ensor, Fricker, \& Girdwood, 1985; Ortiz \& Smith, 1994; Weber, 1979). In addition, solid waste management facilities can pose a hazard to safe aircraft operations if these facilities are located near airports or result in birds making regular movements across an airfield or through critical airspace (Baxter \& Allan, 2006; Belant, Ickes, \& Seamans, 1998; Cook, Rushton, Allan, \& Baxter, 2008). In the United States, the Federal Aviation Administration (FAA) currently recommends municipal solid waste management facilities (e.g., landfills, transfer stations) not be sited within eight $\mathrm{km}$ of an airport [see FAA Advisory Circulars (AC) 150/5200-33B and 150/5200-34] due to the potential risks of increased bird strikes (i.e., collisions between birds and aircraft) associated with these types of facilities. 
Table 1

Geographic location and distribution of transfer station building designs among 27 transfer stations and 4 reference sites studied during 2003-2005. ${ }^{\text {a }}$

\begin{tabular}{|c|c|c|}
\hline $\begin{array}{l}\text { Geographic } \\
\text { region of the USA }\end{array}$ & States & $\begin{array}{l}\text { Building designs } \\
\text { (number of each) }\end{array}$ \\
\hline Northeast & $\mathrm{MA}, \mathrm{CT}$ & $\begin{array}{l}\text { Reference site (1) } \\
\text { Completely open (1) } \\
\text { 3-Sided bays (2) } \\
\text { Fully enclosed (1) }\end{array}$ \\
\hline Midwest & $\mathrm{OH}, \mathrm{MO}$ & $\begin{array}{l}\text { Reference site (1) } \\
\text { Completely open (1) } \\
\text { 3-Sided bays (5) }\end{array}$ \\
\hline Northwest & WA & $\begin{array}{l}\text { Reference site (1) } \\
\text { Completely open (1) } \\
\text { 3-Sided open (3) } \\
\text { Semi-enclosed (5) } \\
\text { Fully enclosed (2) }\end{array}$ \\
\hline Southwest & $A Z$ & $\begin{array}{l}\text { Reference site (1) } \\
\text { 3-Sided open (2) } \\
\text { 3-Sided bays (2) } \\
\text { Fully enclosed (2) }\end{array}$ \\
\hline
\end{tabular}

a A fully enclosed waste transfer station in Connecticut and a semi-enclosed transfer station in California were also studied. However, these two facilities were not included in data analyses because of they had an overriding influence and biased the data.

Similar to other solid waste handling and treatment facilities, transfer stations have the potential to attract nuisance birds and therefore increase the potential for conflict situations. Little information is available regarding the attractiveness of transfer stations by birds. Previous studies of the bird use of transfer stations have been very limited in geographic location (i.e., within a single county) and in the number of facilities studied (Caccamise, Reed, \& Romanowski, 1996; Gabrey, 1997; Stevens, Schafer, \& Washburn, 2005). Whether or not transfer stations of various building designs (e.g., open-sided, fully enclosed) are used by birds, particularly on a national scale, is currently unknown. I examined bird use of transfer stations of various building designs located in different geographic regions of the United States.

The objectives of my study were to: (1) document and quantify avian use of transfer stations, (2) determine if the building design characteristics of transfer stations influence their attractiveness to birds, and (3) determine if season, geographic location, operational characteristics of transfer stations, or other factors influence bird use of waste transfer stations.

\section{Methods}

\subsection{Study areas}

I conducted an inventory of transfer stations available for study in various regions of the United States using a variety of information sources (e.g., state listings of transfer stations, personal contacts within the waste management industry). During the inventory period, I personally visited each transfer station and reference site, met with management personnel at each facility, and obtained direct on-site information regarding pertinent transfer station building design and operational characteristics of each facility. Ultimately, 29 transfer stations and 4 reference sites (i.e., grocery stores) located within seven states (Arizona, Ohio, Massachusetts, Connecticut, Washington, California, and Missouri) were selected for study (Table 1). These states were selected to represent different geographic regions of the United States (e.g., northeast, southwest).

\subsection{Bird observations}

Bird observations were conducted between 18 October 2004 and 20 January 2006 using a modified fixed-radius point count surveys (Hutto, Pletschet, \& Hendricks, 1986; Sorace et al., 2000). Two 15-min point counts were conducted successively at two predetermined observation locations, selected to provide (in sum) a complete view of the facility. At most facilities, the area being surveyed was essentially a semi-circular area that allowed for a clear view of only one side of the facility.

Avian surveys were conducted on two randomly chosen days per week (Monday through Friday) for a 1-year period at each reference site and transfer station. In total, each transfer station and reference site was surveyed from 44 to 111 days (average of 94 days) during this period, resulting in an average of $47 \mathrm{~h}$ of observation per facility. Bird surveys were randomly stratified so that individual surveys were conducted evenly during morning (06:00-11:00 h), mid-day (11:00-16:00 h), and evening (16:00-21:00 h) periods each month at each individual location.

A total of 18 individuals (including myself) conducted the bird observations at the transfer stations and reference sites during the study. Prior to starting the surveys, I personally trained all observers individually to ensure consistency in data collection and categorization of bird behaviors among observers. During each individual 15-min survey, the number and behavior of all birds that were observed within $100 \mathrm{~m}$ (328 feet) of the transfer station or reference site were recorded. Bird behavior was recorded by species and placed into 1 of 8 categories: (1) "pass" flying over the site; (2) "locally" flying over or around the site; (3) loafing (i.e., resting) on the ground; (4) foraging on the ground or in vegetation; (5) loafing on a refuse-transport vehicle; (6) foraging on a refuse-transport vehicle; (7) loafing or in the transfer station or building; (8) feeding on or in the transfer station or building.

\subsection{Transfer station building designs}

Although considerable variation existed in the design and 'openness' of transfer station buildings, I placed each facility into 1 of 5 categories: 'completely open', '3-sided open', '3-sided bays', 'semienclosed', and 'fully enclosed' (Table 1). Completely open transfer stations $(n=3)$ had no walls or were surrounded by only a chain-link fence (Fig. 1a). Transfer stations classified as 3 -sided open $(n=5)$ had three walled sides and the fourth side was completely open (Fig. 1b). Three-sided bays facilities $(n=9)$ had three walled sides and the fourth side consisted of a series of bay doors that were left open (Fig. 1c). Semi-enclosed transfer stations $(n=6)$ had four walled or chain-link-fenced sides with large openings on two sides of the building (Fig. 1d). Fully enclosed transfer stations $(n=6)$ had four walled sides and small doors that were just large enough to allow refuse-collection vehicles to enter or exit (Fig. 1e). Reference sites (i.e., grocery stores) consisted of a building similar in size and shape to transfer station buildings where no refuse was present.

\subsection{Transfer station characteristics}

Site-specific information about transfer stations, including the average tons per day of refuse processed at the facility and the size of the transfer station building or work area (in $\mathrm{m}^{2}$ ), was obtained by interviewing the management personnel at each facility. In addition, I determined the linear distance (in $\mathrm{km}$ ) from each individual transfer station and reference site to the nearest major body of water (e.g., ocean, lake, or major river).

During each 15-min survey, the number of commercial (i.e., curbside collection trucks) and private (e.g., pickup trucks and trailers) vehicles that were present or arrived at the facility were counted. Any instances where refuse fell off or out of a refusetransport vehicle was also recorded. In addition, at the start of each individual survey, the amount of uncontained refuse that 

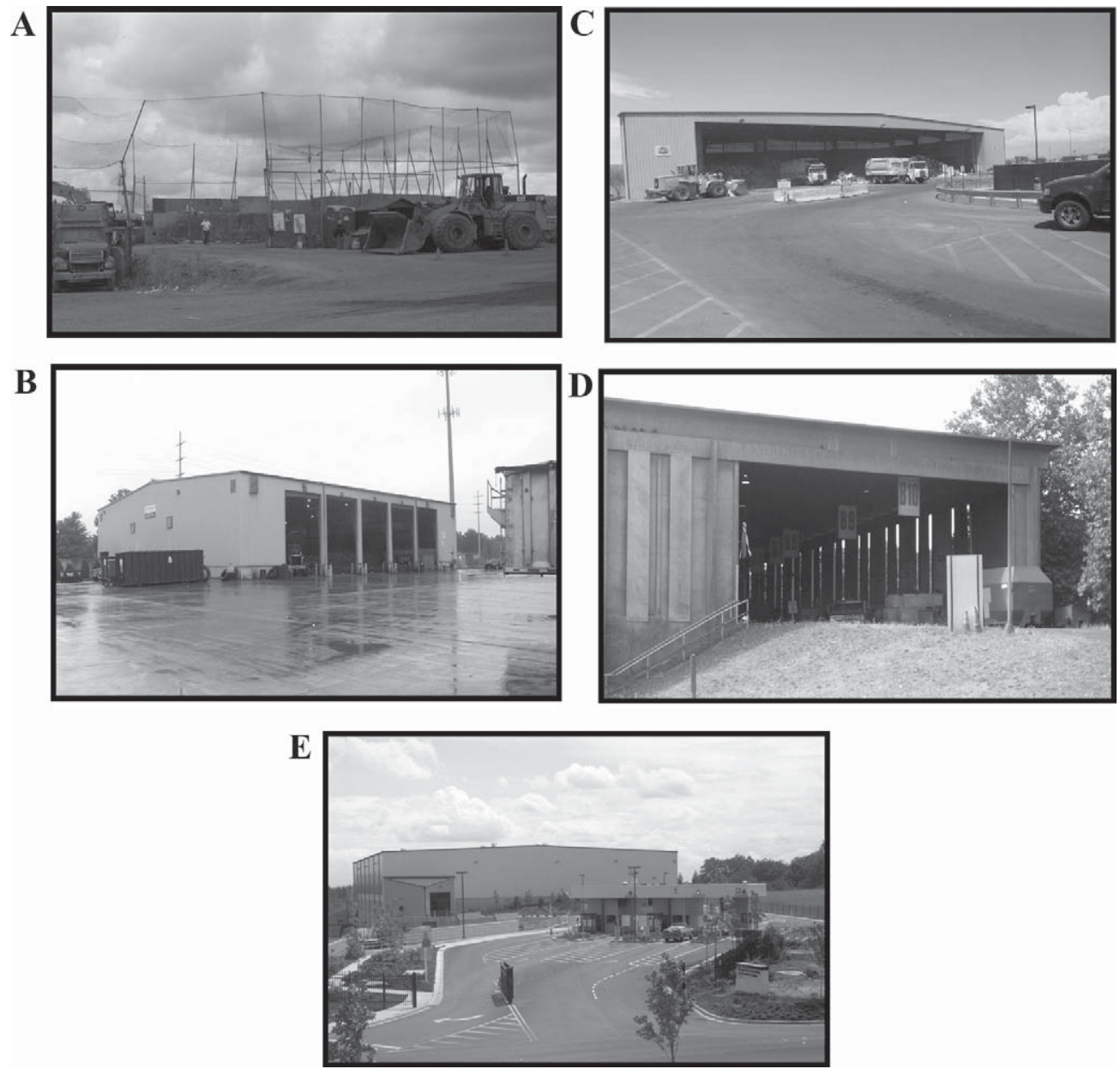

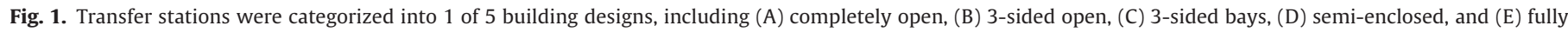
enclosed.

was present outside the building was visually estimated and recorded into 1 of 4 uncontained refuse site rating categories: 'none', 'slight', 'moderate', or 'heavy'. Prior to starting surveys, I trained all observers individually to ensure consistency in visual estimation of uncontained refuse among observers.

\subsection{Data analyses}

For the purposes of data analyses and because these observations were not independent, I determined the maximum number of total birds observed using the facility between the two 15-min surveys conducted at each facility on each observation day to provide one survey per facility for each observation day. In addition, in order to consider only birds actually associated with (e.g., using) the transfer station and reference site buildings, birds with the "pass flying', 'locally flying', 'loafing on the ground', and 'feeding on the ground' activity codes were removed from the data prior to further statistical analyses.

One of the fully enclosed transfer stations had an average of 1176 total birds using the facility per survey, more than 6 times higher than the mean number of total birds using the other fully enclosed transfer stations. In addition, the semi-enclosed transfer station in California had an average of 630 birds using the facility per survey, more than 7 times higher than the mean number of total birds using the other semi-enclosed transfer stations. The reasons for such high levels of bird use at these 2 waste transfer stations are unknown. Because these individual transfer stations had an overriding influence and biased the data, the bird observation data from these 2 facilities were removed prior to analyses.

Bird observation data were not normally distributed and could not be transformed satisfactorily. Therefore, use among transfer stations and reference sites by total birds (all species combined), European starlings, and gulls (comprised of several species) were compared using Kruskal-Wallis tests (test statistic H; Zar, 1996). No gulls were observed using transfer stations in Arizona or the facility located in Missouri; therefore, transfer station bird observation data from these states were not used in analyses of the number of gulls using transfer stations. Also, I used Kruskal-Wallis tests to compare median bird use of reference sites and transfer stations among seasons (defined as: winter = December, January, and February; spring = March, April, and May; summer = June, July, and August; fall =September, October, and November) and across geographic locations of the United States (i.e., northeast, midwest, southwest, pacific northwest).

Spearman's rank correlation analyses were used to determine if relationships existed between transfer station characteristics (e.g., transfer station building size, distance to major water body, percent of uncontained refuse site ratings within categories) and the median number of total birds, European starlings, and gulls using transfer stations per survey (Zar, 1996). Differences were considered significant at $p \leq 0.05$ and all analyses were conducted using SAS statistical software version 9.1 (SAS Institute, Cary, NC). 


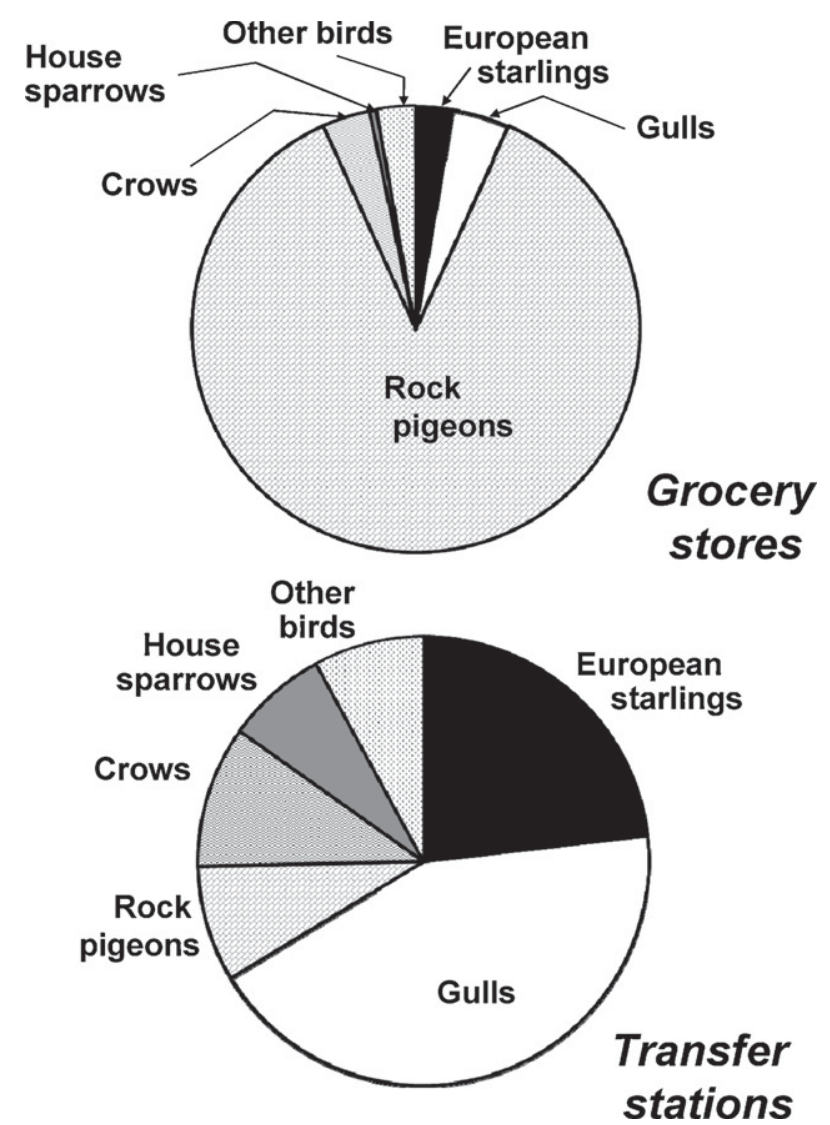

Fig. 2. Proportion of birds species/groups observed using grocery stores $(n=4)$ and waste transfer stations $(n=27)$ during 2003-2005.

\section{Results}

\subsection{Bird observations}

A total of 15 bird species were observed using grocery stores (reference sites), whereas 49 bird species were observed using waste transfer stations during the study. Rock pigeons $(86.4 \%$ of all birds observed), gulls (4.1\%), and crows (3.5\%) were the bird species/groups most frequently observed using grocery stores (Fig. 2). Gulls (43.1\%), European starlings (23.2\%), and crows (10.2\%) were the most frequently observed bird species/groups using waste transfer stations (Fig. 2).

\subsection{Transfer station building designs}

The median number of birds using transfer stations of various building design (ranging from 15 to 35 total birds observed per survey among the transfer station building types) was 7.5-17.5 orders of magnitude higher than the median number of total birds observed using reference sites ( 2 birds per survey; $H=271.8$, $p<0.001$ ). European starlings were observed using transfer stations of all different building designs at a higher level than reference sites $(H=479.1, p<0.001)$. The median number of starlings using 'completely open' and ' 3 -sided, bays' transfer stations were 12 and 1 orders of magnitude higher than the median number of starlings using reference sites. Gulls exhibited a similar pattern, using transfer stations of all different building designs at a higher level than reference sites $(H=310.6, p<0.001)$. The median number gulls using 'completely open' and ' 3 -sided, open' transfer stations were 2-10 times higher than the median number of gulls using reference sites. The median number of total birds (all species) observed using

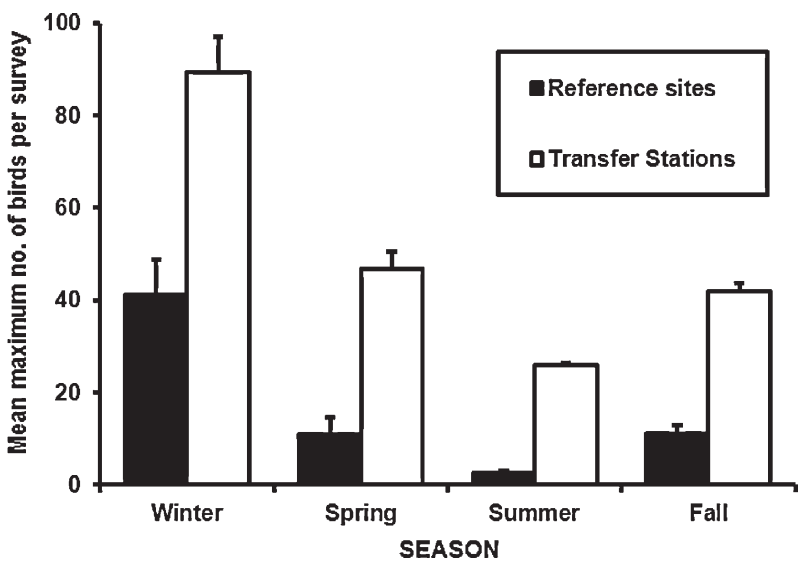

Fig. 3. Mean maximum number of birds (all species) observed per survey ( \pm SE) each season using grocery stores (reference sites) and 27 transfer stations during 2003-2005.

reference sites $(H=21.6, p<0.001)$ and transfer stations $(H=163.1$, $p<0.001)$ varied among the seasons of the year. Bird use of transfer stations was highest during winter months (i.e., December to February) and lowest during summer months (i.e., June to August; Fig. 3). Similarly, use of reference sites and waste transfer stations by European starlings (groceries: $H=21.0, p<0.001$; transfer stations: $H=125.9, p<0.001$ ) and gulls (groceries: $H=33.2, p<0.001$; transfer stations: $H=98.1, p<0.001$ ) followed a similar pattern.

Given the influence of season on bird use patterns, I conducted additional analyses of bird use at waster transfer stations during winter (December, January, February) and summer (June, July, and August). In winter, the median number of birds using transfer stations of various building design was $6-16.5$ orders of magnitude higher than the median number of total birds observed using reference sites $(H=76.3, p<0.001$; Table 2$)$. Starling $(H=162.1$, $p<0.001)$ and gull use $(H=121.7, p<0.001)$ of waste transfer stations during winter months followed a similar pattern. Overall, bird use of 'completely' open transfer stations was higher than bird use of 'semi-enclosed' and 'fully enclosed' waste transfer stations (Table 2). During summer months, median total bird use of waste transfer stations was 10-17 times higher than at grocery stores $(H=98.9, p<0.001$; Table 3$)$. However, transfer station building design did not influence total bird use during summer months (Table 3).

Bird use of transfer stations varied considerably within those buildings that were of the same design (Fig. 4). Within a given building design category, starling, and gull use of transfer stations was highly variable, ranging from little to substantial.

\subsection{Transfer station characteristics}

The geographic location of individual transfer stations influenced the amount of bird use at those facilities. The median number of birds using waste transfer stations in Ohio ( 35.5 birds per survey) was over twice that of the median bird use of waste transfer stations in Arizona ( 15 birds per survey); whereas bird use of facilities in Massachusetts and Connecticut (median of 19 birds per survey) and the state of Washington (median of 20 birds per survey) were intermediate to other states $(H=113.0, p<0.001)$. European starling use of transfer stations varied $(H=544.1, p<0.001)$ among states; the median number of starlings using transfer stations in northeast and midwest states was 10 orders of magnitude higher than starling use of transfer stations in the southeast and Pacific northwest. Overall, use of waste transfer stations by gulls in Ohio was twice that of gulls using transfer stations in Washington $(H=26.7$, $p<0.001$ ). 
Table 2

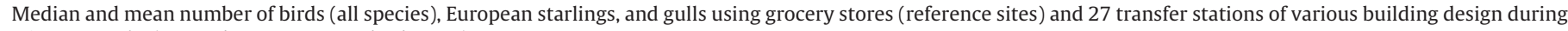
winter months (December, January, and February).

\begin{tabular}{|c|c|c|c|c|}
\hline Transfer station building design & $n$ & Median & Mean \pm SE & $\mathrm{CV}$ \\
\hline \multicolumn{5}{|l|}{ All birds ${ }^{\mathrm{a}}$} \\
\hline Grocery (reference) & 94 & $6 A^{b}$ & $41.2 \pm 7.5$ & 177 \\
\hline Completely open & 82 & $101 \mathrm{~B}$ & $123.4 \pm 13.2$ & 97 \\
\hline 3-Sided, open & 98 & $65 \mathrm{C}$ & $99.0 \pm 10.8$ & 108 \\
\hline 3-Sided, bays & 202 & $45 \mathrm{C}$ & $91.6 \pm 8.8$ & 137 \\
\hline Semi-enclosed ${ }^{c}$ & 111 & $29 \mathrm{D}$ & $45.5 \pm 4.5$ & 104 \\
\hline Fully enclosed ${ }^{\mathrm{c}}$ & 113 & $26 \mathrm{D}$ & $94.9 \pm 13.6$ & 153 \\
\hline \multicolumn{5}{|l|}{ European starlings } \\
\hline Grocery (reference) & 94 & $0 A^{b}$ & $1.3 \pm 0.5$ & 354 \\
\hline Completely open & 82 & $46 \mathrm{~B}$ & $76.2 \pm 12.3$ & 146 \\
\hline 3-Sided, open & 98 & OC & $27.3 \pm 5.8$ & 212 \\
\hline 3-Sided, bays & 202 & $8 \mathrm{D}$ & $40.7 \pm 5.4$ & 190 \\
\hline Semi-enclosed ${ }^{c}$ & 111 & $10 \mathrm{D}$ & $20.4 \pm 2.4$ & 125 \\
\hline Fully enclosed $^{\mathrm{c}}$ & 113 & OC & $14.8 \pm 3.7$ & 266 \\
\hline \multicolumn{5}{|l|}{ Gulls d,e } \\
\hline Grocery (reference) & 74 & $0 A^{b}$ & $2.3 \pm 0.5$ & 200 \\
\hline Completely open & 82 & $25 \mathrm{~B}$ & $29.7 \pm 5.8$ & 127 \\
\hline 3-Sided, open & 58 & $57 \mathrm{~B}$ & $63.5 \pm 7.4$ & 88 \\
\hline 3-Sided, bays & 138 & $1 \mathrm{C}$ & $51.5 \pm 8.1$ & 186 \\
\hline Semi-enclosed $^{c}$ & 111 & $0 \mathrm{~A}$ & $0.9 \pm 0.1$ & 160 \\
\hline Fully enclosed ${ }^{\mathrm{c}}$ & 73 & $4 \mathrm{C}$ & $80.1 \pm 15.5$ & 165 \\
\hline
\end{tabular}

a Consists of the maximum number of birds of all species observed per survey.

b Medians within the same column with the same letter are not different $(p>0.05)$ according to a Kruskal-Wallis test.

c Two waste transfer stations (one fully enclosed and one semi-enclosed) were excluded from these analyses due to their overwhelming influence on the data.

d Consists of the total number of gulls from 8 species observed per survey.

e For analyses of gulls, transfer stations in Arizona and Missouri were excluded as gulls were not observed at those facilities.

The size of the transfer stations buildings ranged from 235 to $9700 \mathrm{~m}^{2}$. The median number of total birds using transfer stations was positively correlated with the size of the transfer station building $\left(r_{s}=0.41, p=0.02\right)$. Similarly, the median number of gulls using transfer stations was positively correlated with transfer station building size $\left(r_{s}=0.45, p=0.04\right)$. The distance a transfer station was to a major water body (range $=0.5-18 \mathrm{~km}$ ) and the average amount of refuse processed by a facility ( range $=40-1600$ tons per day) were not correlated (all $p>0.05$ ) with bird use of transfer stations.

At 27 transfer stations studied during a one-year period, a total of 26,045 refuse collection trucks and transport vehicles were counted (average of 5.2 vehicles per survey). Overall, commercial trucks accounted for $58 \%$ of the trucks, whereas private vehicles accounted for $42 \%$. The proportion of commercial compared to private vehicles varied among facilities; transfer stations in the southeast and the midwest had a high proportion of commercial trucks (82-94\%) whereas the proportion of private vehicles was equal to commercial trucks in the northeast. At transfer stations in the northwest, private vehicles accounted for $68 \%$ of the total trash trucks. Refuse was rarely observed falling off from commercial trucks or private vehicles, occurring only $0.4 \%$ of the time (a total of 129 occasions).

Table 3

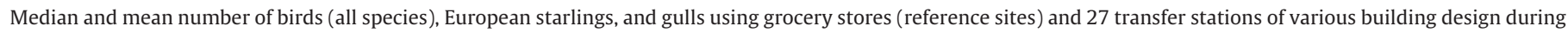
summer months (June, July, and August).

\begin{tabular}{|c|c|c|c|c|}
\hline Transfer station building design & $n$ & Median & Mean \pm SE & $\mathrm{CV}$ \\
\hline \multicolumn{5}{|l|}{ All birds ${ }^{a}$} \\
\hline Grocery (reference) & 96 & $1 \mathrm{~A}^{\mathrm{b}}$ & $2.6 \pm 0.4$ & 159 \\
\hline Completely open & 72 & $15 \mathrm{~B}$ & $23.2 \pm 3.3$ & 122 \\
\hline 3-Sided, open & 107 & $10 \mathrm{~B}$ & $17.5 \pm 1.8$ & 104 \\
\hline 3-sided, bays & 227 & $11 \mathrm{~B}$ & $38.0 \pm 4.6$ & 181 \\
\hline Semi-enclosed ${ }^{c}$ & 115 & $12 \mathrm{~B}$ & $14.4 \pm 0.9$ & 68 \\
\hline Fully enclosed ${ }^{\mathrm{c}}$ & 118 & $17 \mathrm{~B}$ & $23.4 \pm 3.5$ & 163 \\
\hline \multicolumn{5}{|l|}{ European starlings } \\
\hline Grocery (reference) & 96 & $0 \mathrm{~A}^{\mathrm{b}}$ & $0.3 \pm 0.1$ & 341 \\
\hline Completely open & 72 & $7 \mathrm{~B}$ & $12.4 \pm 2.0$ & 137 \\
\hline 3-Sided, open & 107 & $0 \mathrm{C}$ & $3.6 \pm 1.3$ & 368 \\
\hline 3-Sided, bays & 227 & $0 \mathrm{D}$ & $10.4 \pm 1.5$ & 219 \\
\hline Semi-enclosed ${ }^{\mathrm{c}}$ & 115 & $0 \mathrm{C}$ & $3.5 \pm 0.7$ & 205 \\
\hline Fully enclosed ${ }^{\mathrm{c}}$ & 118 & $0 \mathrm{C}$ & $3.7 \pm 3.3$ & 351 \\
\hline \multicolumn{5}{|l|}{ Gulls d,e } \\
\hline Grocery (reference) & 71 & $0 \mathrm{~A}^{\mathrm{b}}$ & $0.2 \pm 0.1$ & 491 \\
\hline Completely open & 72 & $0 \mathrm{~A}$ & $1.8 \pm 1.0$ & 465 \\
\hline 3-Sided, open & 58 & $4 \mathrm{~B}$ & $6.1 \pm 1.0$ & 120 \\
\hline 3-Sided, bays & 153 & $0 \mathrm{C}$ & $29.4 \pm 5.9$ & 251 \\
\hline Semi-enclosed ${ }^{\mathrm{c}}$ & 115 & $0 \mathrm{~A}$ & $0.2 \pm 0.1$ & 490 \\
\hline Fully enclosed ${ }^{\mathrm{c}}$ & 69 & $0 \mathrm{~A}$ & $4.0 \pm 1.2$ & 254 \\
\hline
\end{tabular}

a Consists of the maximum number of birds of all species observed per survey.

b Medians within the same column with the same letter are not different $(p>0.05)$ according to a Kruskal-Wallis test.

c Two waste transfer stations (one fully enclosed and one semi-enclosed) were excluded from these analyses due to their overwhelming influence on the data.

d Consists of the total number of gulls from 8 species observed per survey.

e For analyses of gulls, transfer stations in Arizona and Missouri were excluded as gulls were not observed at those facilities. 


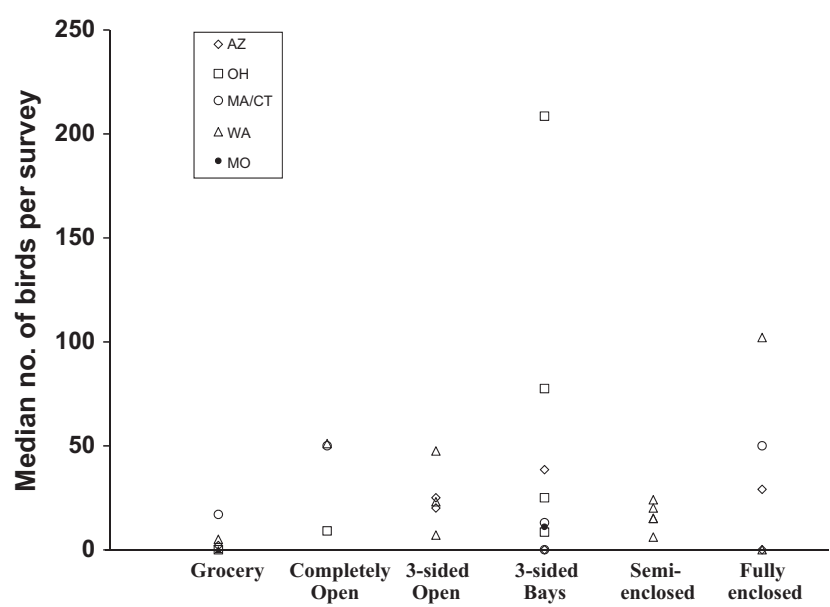

Fig. 4. Median maximum number of birds (all species) observed per survey using individual grocery stores (reference sites) and 27 transfer stations of various building design during 2003-2005.

The median number of total birds using transfer stations was positively correlated with the percent of uncontained refuse site ratings categorized as 'moderate' $\left(r_{s}=0.56, p=0.002\right)$ and as 'heavy' $\left(r_{s}=0.45, p=0.02\right)$. Transfer station use by European starlings was not correlated with any of the percent of uncontained refuse site ratings (all $p>0.05$ ). The median number of gulls using transfer stations was positively correlated with the percent of uncontained refuse site ratings categorized as 'heavy' $(r=0.47, p=0.03)$.

\section{Discussion}

Approximately 50\% of all of the birds observed using transfer stations in this study were European starlings. European starlings cause a variety of nuisance and public health problems through nest building, defecation, and transmission of diseases to humans, livestock, and other birds (Feare, 1984; Linz, Homan, Gaukler, Penry, \& Bleier, 2007; Weber, 1979). Starlings used transfer station buildings as nesting sites, loafed on or in the facilities and refuse-transport vehicles, and frequently were observed foraging on refuse piles within the trash stations or on uncontained litter outside of the buildings. European starlings are not only a nuisance and public health concern at these facilities, they also represent a significant risk to safe aircraft operations (Dolbeer, Wright, \& Cleary, 2000; Dolbeer, Wright, Weller, \& Begier, 2009), particularly if their movements to and from transfer stations cause them to traverse through critical airspace frequently used by aircraft and across runways.

Gulls, consisting of 8 species, accounted for almost one-third of the birds observed using transfer stations, whereas very few gulls were observed at reference sites (i.e., grocery stores). Ring-billed gulls (Larus delawarensis), herring gulls (Larus argentatus), California gulls (Larus californicus), and western gulls (Larus occidentalis) were the most abundant gulls at transfer stations. The specific gull species present at individual transfer stations was directly related to the geographic location of those facilities and the geographic distribution of the gull species themselves (see Pierotti \& Good, 1994; Ryder, 1993 for examples). In addition to loafing on transfer station buildings and refuse-transport vehicles, gulls were often observed actively foraging upon refuse piles within the trash station buildings and among moving heavy equipment and trucks.

Rock pigeons were frequently observed roosting, nesting, or feeding on refuse piles in transfer station buildings. Crows were frequently observed using transfer stations; most commonly loafing or feeding on refuse-transport vehicles that were parked at the facilities. Similar to starlings and gulls, rock pigeon and crow use of transfer stations is not only a nuisance and public health and safety concern (Dolbeer et al., 2009; Weber, 1979; Williams \& Corrigan, 1994).

Overall, the design of transfer station buildings (more specifically the 'openness' of these buildings) influenced on the amount of bird use (in particular nuisance species such as gulls and starlings) at those facilities. Waste transfer stations that were 'completely open' had considerable more bird use (in particular European starlings) compared to transfer stations that were more 'enclosed'. High variability in the amount of bird use was evident for transfer stations of similar building design, in particular with the " 3 -sided, bays', 'semi-enclosed' and 'fully enclosed' facilities. Notably, there were several facilities of these designs that had minimal bird use and two facilities that bird use was several orders of magnitude higher than the other waste transfer stations being studied. Overall, bird use of transfer stations was higher at facilities with larger buildings and those that processed more refuse; I suspect more refuse was available to foraging birds at transfer stations with a larger capacity for refuse throughput.

Findings from this study suggest the building design of a waste transfer station is not the only factor that might influence bird use of a facility. A variety of factors, including time of year, the geographic location, operational procedures, and other issues likely influence the amount of bird use that occurs at a given waste transfer station.

The amount of bird use of transfer stations varied considerably among seasons during this study. Bird use of transfer stations was greatest during the winter months and least during the summer months. This trend was evident for both European starlings and gulls. During summer months, European starlings are likely to be foraging for natural foods of terrestrial origin, such as insects and plant materials (e.g., seeds and fruits) (Cabe, 1993; Feare, 1984; Fischl \& Caccamise, 1987). Similarly, gulls are more likely to exploit food resources from aquatic systems during summer months (Duhem, Vidal, Roche, \& Legrand, 2005; Gilliland, Ankney, \& Hicklin, 2004; Pierotti \& Annett, 1991). In contrast, during winter months food resources for starlings and gulls are much more limited and thus anthropogenic food resources (e.g., refuse at transfer stations) might be more much important and used with greater frequency. Belant, Seamans, Gabrey, and Ickes (1993) found that breeding herring gulls utilized natural food resources (e.g., fish) rather than foraging on refuse at landfills; however, anthropogenic food sources (e.g., household refuse at landfills) were important to post-breeding herring gulls.

The geographic location of an individual transfer station appears to have strong influence on the amount of bird use of that facility. Not unexpectedly, gull use of transfer stations was highest at facilities located near coastal areas or the Great Lakes (e.g., Massachusetts, Ohio) but non-existent at transfer stations in inland areas (e.g., Arizona). The number of total birds, in addition to the individual species involved, that use an individual transfer station for nesting, loafing, and foraging is likely a consequence of the abundance and diversity of bird species present within that geographic location. For example, crows were most abundant and used transfer stations located in the northwest and the northeast areas of the USA, but were observed far less frequently at transfer stations in other areas. This finding is consistent with the general abundance of crows across their geographic range (Verbeek \& Caffrey, 2002).

Operational procedures at facilities influenced the amount of bird use of transfer stations. The abundance of total birds, European starlings, and gulls using transfer stations was positively related to the proportion of uncontained refuse site ratings categorized as 'moderate' or 'heavy', suggesting that the amount of litter (i.e., uncontained refuse) outside of the transfer station buildings themselves influences the use of these facilities by birds. Higher amounts of litter around the facility grounds might be more visible to birds that are flying near the facility and thus potentially could attract them to the sites. On-site management practices that increase the 
“cleanliness" of transfer stations, such as periodically removing litter and uncontained trash from refuse-transport vehicle movement and parking areas near the transfer station building, might therefore reduce the use of these facilities by birds.

\section{Conclusions}

Overall, the findings from this study demonstrate that avian use of transfer stations can be substantial, particularly by nuisance birds. High levels of bird use at transfer stations can result in problems associated with the daily operation of the facility, nuisance issues for local residents and adjacent landowners, and human health and safety issues. The amount of bird use among individual transfer stations of the same building design was highly variable. Study findings suggest several factors, including season, geographic location, and operational (on-site) management practices, might be important and influence the amount of bird use at waste transfer stations. Future research specifically evaluating these factors is needed to elucidate their importance. Notably, bird use was minimal at some individual transfer stations. Efforts to reduce the potential for use by nuisance birds should be considered during the planning phase (e.g., siting, building design) for new transfer stations. At existing transfer stations, operational procedures and appropriate wildlife control activities could be conducted to reduce their attractiveness to birds and thus decrease the risk of human-wildlife conflict situations associated with those facilities.

\section{References}

Baxter, A. T., \& Allan, J. R. (2006). Use of raptors to reduce scavenging bird numbers at landfill sites. Wildlife Society Bulletin, 43, 1162-1168.

Belant, J. L., Ickes, S. K., \& Seamans, T. W. (1998). Importance of landfills to urbannesting herring and ring-billed gulls. Landscape and Urban Planning, 43, 11-19.

Belant, J. L., Seamans, T. W., Gabrey, S. W., \& Dolbeer, R. A. (1995). Abundance of gulls and other birds at landfills in northern Ohio. American Midland Naturalist, 134, 30-40.

Belant, J. L., Seamans, T. W., Gabrey, S. W., \& Ickes, S. K. (1993). Importance of landfills to nesting herring gulls. Condor, 95, 817-830.

Benton, C., Khan, F., Monaghan, W., Richards, W. N., \& Sneddon, C. B. (1983). The contamination of a major water supply by gulls (Larus spp.). A study of the problem and remedial action taken. Water Research, 17, 789-798.

Bovea, M. D., Powell, J. C., Gallardo, A., \& Capuz-Rizo, S. F. (2007). The role played by environmental factors in the integration of a transfer station in a municipal solid waste management system. Waste Management, 27, 545-553.

Cabe, P. R. (1993). European starling (Sturnus vulgaris). In A. Poole, \& F. Gill (Eds.), The birds of North America. Philadelphia, PA: The Birds of North America, Inc.

Caccamise, D. M., Reed, L. M., \& Romanowski, J. (1996). Bird strike hazards and waste management facilities in urban landscapes. In Proceedings of the 23rd international bird strike committee meeting London, United Kingdom, (pp. 247-266).

Cook, A., Rushton, S., Allan, J., \& Baxter, A. (2008). An evaluation of techniques to control problem bird species on landfill sites. Environmental Management, 41, 834-843.

Coulson, J. C., Butterfield, J., Duncan, N., \& Thomas, C. (1987). Use of refuse tips by adult British herring gulls Larus argentatus during the week. Journal of Applied Ecology, 24, 789-800.
Dolbeer, R. A., Wright, S. E., \& Cleary, E. C. (2000). Ranking the hazard level of wildlife species to aviation. Wildlife Society Bulletin, 28, 372-378.

Dolbeer, R. A., Wright, S. E., Weller, J. R., \& Begier, M. J. (2009). Wildlife strikes to civil aircraft in the United States, 1990-2008 (61 pp.). U.S. Department of Transportation, Federal Aviation Administration, Office of Airport Safety and Standards, Serial Report No. 15, Washington, DC, USA.

Duhem, C., Vidal, E., Roche, P., \& Legrand, J. (2005). How is the diet of yellowlegged gull chicks influenced by parents' accessibility to landfills? Waterbirds, 28, 46-52.

Environmental Protection Agency. (2002). Waste transfer stations: A manual for decision-making (54 pp.). U.S. Environmental Protection Agency, Solid Waste and Emergency Response, EPA530-R-02-002, Washington, DC, USA.

Feare, C. J. (1984). The starling. Oxford, United Kingdom: Oxford University.

Fischl, J., \& Caccamise, D. F. (1987). Relationships of diet and roosting behavior in the European starling. American Midland Naturalist, 117, 395-404.

Gabrey, S. (1997). Bird and small mammal abundance at four types of wastemanagement facilities in northeast Ohio. Landscape and Urban Planning, 37, 223-233.

Gilliland, S. G., Ankney, C. D., \& Hicklin, P. W. (2004). Foraging ecology of great blackbacked gulls during brood-rearing in the Bay of Fundy New Brunswick. Canadian Journal of Zoology, 82, 1416-1426.

Hutto, R. L., Pletschet, S. M., \& Hendricks, P.(1986). A fixed-radius point count method for nonbreeding and breeding season use. Auk, 103, 593-602.

Kollikkathara, N., Feng, H., \& Stern, E. (2009). A purview of waste management evolution: Special emphasis on the USA. Waste Management, 29, 974-985.

Linz, G. M., Homan, H. J., Gaukler, S. M., Penry, L. B., \& Bleier, W. J. (2007). European starlings: A review of an invasive species with far-reaching impacts. In G. W. Witmer, W. C. Pitt, \& K. A. Fagerstone (Eds.), Managing vertebrate invasive species: Proceedings of an international symposium (pp.378-386). Fort Collins, CO: U.S. Department of Agriculture, Animal Plant Health Inspection Service, Wildlife Services, National Wildlife Research Center.

Monaghan, P., Sheddon, C. B., Ensor, K., Fricker, C. R., \& Girdwood, R. W. A. (1985). Salmonella carriage by herring gulls (Larus argentatus) in the Clyde area. Journal of Animal Ecology, 22, 669-680.

Ortiz, N. E., \& Smith, G. R. (1994). Landfill sites, botulism, and gulls. Epidemiology and Infection, 112, 385-391.

Pierotti, R. J., \& Annett, C. A. (1991). Diet choice in the herring gull: Constraints imposed by reproductive and ecological factors. Ecology, 72, 319-328.

Pierotti, R. J., \& Good, T. P. (1994). Herring gull (Larus argentatus). In A. Poole, \& F. Gill (Eds.), The birds of North America. Philadelphia, PA: The Birds of North America, Inc.

Rahman, M., \& Kuby, M. (1995). A multiobjective model for locating solid waste transfer facilities using an empirical opposition function. Infor, 33, 34-49.

Rock, P. (2005). Urban gulls: Problems and solutions. British Birds, 98, 338-355.

Ryder, J. P. (1993). Ring-billed gull (Larus delawarensis). In A. Poole, \& F. Gill (Eds.), The birds of North America. Philadelphia, PA: The Birds of North America, Inc.

Sorace, A., Gustin, M., Calvario, E., Ianniello, L., Sarrocco, S., \& Carere, C. (2000). Assessing bird communities by point counts: Repeated sessions and their duration. Acta Ornithology, 35, 197-202.

Stevens, M. R., Schafer, L. M., \& Washburn, B. E. (2005). Trash and water: managing on-airport wildlife attractants at Paine Field Washington. In Bird strike committee proceedings, Bird Strike Committee, USA/Canada, 7th annual meeting Vancouver, Canada.

Verbeek, N. A., \& Caffrey, C. (2002). American crow (Corvus brachyrhynchos). In A. Poole, \& F. Gill (Eds.), The birds of North America. Philadelphia, PA: The Birds of North America, Inc.

Weber, W. J. (1979). Health hazards from pigeons, starlings and English sparrows. California: Thomson.

Williams, D. E., \& Corrigan, R. M. (1994). Pigeons (rock doves). In S. E. Hygnstrom, R. M. Timm, \& G. E. Larson (Eds.), Prevention and control of wildlife damage (pp. E87-E96). Lincoln, NE: University of Nebraska Cooperative Extension Service.

Zar, J. H. (1996). Biostatistical analysis. New Jersey: Prentice Hall.

Zhen-shan, L., Lie, Y., Xiao-Yan, Q., \& Yu-mei, S. (2009). Municipal solid waste management in Beijing City. Waste Management, 29, 2596-2599. 


\title{
Corrigendum
}

\section{Corrigendum to "Avian use of solid waste transfer stations" [Landscape Urban Plan. 104 (2012) 388-394]}

\author{
Brian E. Washburn* \\ United States Department of Agriculture, Wildlife Services, National Wildlife Research Center, 6100 Columbus Avenue, Sandusky, OH 44870, USA
}

The author would like to acknowledge a few contributors that were regrettably omitted from the published version of his article.

I would like to thank the more than 25 United States Department of Agriculture, Animal Plant Health Inspection Service, Wildlife Services (USDA/APHIS/WS) personnel whose dedication and assistance made this study possible. Access to facilities was graciously provided by numerous private companies and municipalities. The USDA/APHIS/WS National Wildlife Research Center Institutional Animal Care and Use Committee approved procedures involving wildlife (QA-1134). The Federal Aviation Administration (FAA) provided funded and support. Opinions expressed in this study do not necessarily reflect current FAA policy decisions governing the control of wildlife on or near airports. I thank T. DeVault, B. Blackwell, T. Seamans, P. Schmidt, and 2 anonymous reviewers for helpful comments on this manuscript.

DOI of original article: 10.1016/j.landurbplan.2011.11.014.

* Tel.: +1 419625 0242; fax: +1 4196258465 .

E-mail address: brian.e.washburn@aphis.usda.gov 